\title{
Publicações brasileiras na perspectiva vigotskiana
}

\author{
Jefferson Mainardes* $e$ \\ Angel Pino**
}

Este levantamento bibliográfico é uma reprodução parcial de um trabalho de pesquisa realizado por Jefferson Mainardes e publicado em J. B. Martin (org.) "Na perspectiva de L. S. Vygotsky", Londrina: Quebra Nozes, 1999, pp. 81-102. A finalidade de incluí-lo aqui é a de oferecer ao leitor uma visão, mesmo incompleta, de trabalhos produzidos no Brasil em torno das idéias de Vigostki, o que dá uma leve idéia da sua penetração nos nossos meios.

Conforme afirma Jefferson, a teoria de Vigotski começou a ter entrada no Brasil, de modo lento, na segunda metade da década de 70. $\mathrm{Na}$ década de 80, em universidades como Unicamp e PUC/SP, foram se formando grupos de estudiosos da obra desse autor que influenciaram a formação de outros grupos em outras universidades de São Paulo, Minas Gerais e Rio de Janeiro. O contexto histórico e político da década de 80 , principalmente com o processo de redemocratização do país, oferecia condições favoráveis à retomada das discussões educacionais numa perspectiva crítica, assim como à implementação de medidas inovadoras nos sistemas de ensino e à reação contra o dogmatismo teórico que predominara na década anterior. Em 1984, Martins Fontes publicava a versão brasileira de Mind in Society ( $A$ formação social da mente) e, em 1987, a de Tought and Language (Pensamento e linguagem), permitindo o primeiro acesso às idéias de Vigotski. Já no final da década de 80 e início da década de 90, algumas redes de ensino basearam-se em contribuições desta teoria para a definição de propostas curriculares.

\footnotetext{
*Professor da Universidade Estadual de Ponta Grossa

** Faculdade de Educação, Unicamp.
} 
A partir do início da década de 90, começam a surgir as primeiras publicações sobre Vigotski, principalmente artigos: em parte, tratando de questões conceituais e metodológicas e, em parte, de pesquisas tendo como referencial as idéias de do autor.

No final da década de 80 , começam a surgir as primeiras dissertações e teses nessa linha teórica, cujo número vai crescendo paulatinamente, muitas delas publicadas na forma de livros. Só no período de 1986 a 1998, foi possível identificar dezessete teses e quarenta e quatro dissertações, uma grande parte apresentadas à Faculdade de Educação da Unicamp (22) orientadas por docentes do Grupo de Pesquisa Pensamento e Linguagem (GPPL). Em geral, as dissertações e teses apresentam importantes reflexões que contribuíram para o aprofundamento de questões conceituais e metodológicas. Muitas delas tematizam questões de aprendizagem e desenvolvimento no contexto escolar, o papel da linguagem, as interações e mediações sociais, os processos de significação, o jogo simbólico, o desenho infantil etc.

As poucas obras de Vigotski disponíveis em português, todas elas traduções de textos americanos soltos, alguns deles incompletos, somado ao fato de serem essas obras de leitura aparentemente fácil e de o leitor freqüentemente não atentar à fundamentação marxista que marca o pensamento de Vigotski, explicam a diversidade de leituras que revelam os trabalhos ditos de orientação vigotskiana. A rápida difusão das idéias de Vigotski no Brasil nem sempre vai de par a uma compreensão mais profunda do seu pensamento. Na hora atual, como o mostra este levantamento bibliográfico, mesmo incompleto, o leitor interessado pelas idéias de Vigotski dispõe de uma bibliografia local bastante numerosa, além de poder ter acesso a traduções mais confiáveis da maior parte das suas obras. Fato importante para o desenvolvimento da pesquisa histórico-cultural no país.

Entre 1982 e 1984 foram publicadas, em Moscou, as obras escolhidas de Vigotski ${ }^{1}$, em seis volumes, enquanto surgiam, nos Estados Unidos e em Cuba, traduções de trabalhos separados do autor. No fim da década de 80 e na de 90, aparecem as traduções, do russo, das obras escolhidas de Vigotski, em edições bem cuidadas: The Collected Works, 6 vol., Robert W. Rieber and Aaron S. Carton (ed.), New York-London, Plenum Press, e Obras Escogidas, 6 vol. Madrid, Visor-MEC. 


\section{Obras de Vigotski publicadas no Brasil:}

VYGOTSKY, Lev S. A formação social da mente. São Paulo: Martins Fontes, 1984.

VYGOTSKY, Lev S. Pensamento e linguagem. São Paulo: Martins Fontes, 1987.

VYGOTSKY, Lev S.; LURIA, Alexandr R.; LEONTIEV, Alexis N. Linguagem, desenvolvimento e aprendizagem (coletânea de textos). São Paulo: Ícone, 1988.

VYGOTSKY, Lev S.; LEONTIEV, Alexis; LURIA, Alexandr R. Psicologia e pedagogia: bases psicológicas da aprendizagem e do desenvolvimento. São Paulo: Moraes, 1991.

VYGOTSKY, Lev S.; LURIA, Alexandr R. Estudos sobre a história do comportamento: o macaco, o primitivo e a criança. Porto Alegre: Artes Médicas, 1996.

VYGOTSKY, Lev S. Teoria e método em psicologia. São Paulo: Martins Fontes, 1996.

VIGOTSKI, Lev S. Psicologia da Arte. São Paulo: Martins Fontes, 1999.

2. Obras de outros autores vinculados a Vigotski publicadas no Brasil:

ELKONIN, Daniil B. Psicologia do jogo. São Paulo: Martins Fontes, 1998.

LURIA. Aleksandr R. Fundamentos da neuropsicologia. São Paulo: Edusp, 1981.

LURIA, A. R.; YUDOVICH, F.I. Linguagem e desenvolvimento intelectual na criança. Porto Alegre: Artes Médicas, 1985.

LURIA, Alexandr R. Pensamento e linguagem: as últimas conferências de Luria. Porto Alegre: Artes Médicas, 1986.

LURIA, Alexandr R. Desenvolvimento cognitivo: seus fundamentos culturais e sociais. São Paulo: Ícone, 1990.

LURIA, Alexandr R. Curso de psicologia geral: introdução evolucionista à psicologia. vol. I. Rio de Janeiro: Civilização Brasileira, 1991.

LURIA, Alexandr R. Curso de psicologia geral: sensações e percepção. vol. II. Rio de Janeiro: Civilização Brasileira, 1991. 
LURIA, Alexandr R. Curso de psicologia geral: atenção e memória. vol. III. Rio de Janeiro: Civilização Brasileira, 1991.

LURIA, Alexandr R. Curso de psicologia geral: linguagem e pensamento. vol. IV. Rio de Janeiro: Civilização Brasileira, 1991.

LURIA, Alexander R. A construção da mente. São Paulo: Ícone, 1992.

\section{Livros na perspectiva vigotskiana:}

BATISTA, João Batista (org.). Na perspectiva de Vygotsky. São Paulo: Quebra Nozes, Londrina: CEFIL, 1999.

BRAGA, Lucia W. Cognição e paralisia cerebral: Piaget e Vygotsky em questão. Salvador: Sarah Letras, 1995.

BEYER, Hugo Otto. O fazer psicopedagógico: a abordagem de Reuven Fuerstein a partir de Piaget e Vygotsky. Porto Alegre: Medicação, 1996.

CASTORINA, José Antonio; FERREIRO, Emilia; LERNER, Delia; OLIVEIRA, Marta K. de. Piaget-Vygotsky: novas contribuições para o debate. São Paulo: Ática, 1995.

DE CARLO, Marysia Mara R. do P. Se essa casa fosse nossa... instituições e processos de imaginação na Educação Especial. São Paulo: Plexus, 1999.

DUARTE, Newton. Educação escolar, teoria do cotidiano e Escola de Vigotski. Campinas: Autores Associados, 1996.

DUARTE, Newton. Vigotski e o "aprender a aprender": crítica às apropriações neoliberais e pós-modernas da teoria vigotskiana. Campinas: Autores associados, 2000.

FERREIRA, Sueli. Imaginação e linguagem no desenho da criança. Campinas: Papirus, 1998.

FONTANA, Roseli Aparecida C. Mediação pedagógica na sala de aula. Campinas: Autores Associados, 1996.

FREITAS, Maria Teresa de A. O pensamento de Vygotsky e Bakhtin no Brasil. Campinas: Papirus, 1994. 
FREITAS, Maria Teresa de A. Vygotsky e Bakhtin - psicologia e educação: Um intertexto. São Paulo: Ática, 1994.

FREITAS, Maria Teresa de A. (org.). Narrativas de professores: Pesquisando leitura e escrita numa perspectiva sócio-histórica. Rio de Janeiro: Ravil, 1998.

FREITAS, Maria Teresa de A. (org.). Vygotsky - um século depois. Juiz de Fora: Editora da UFJF, 1998.

GÓES, Maria Cecília R. de; SMOLKA, Ana Luiza B. (orgs.). A significação nos espaços educacionais: Interação social e subjetivação. Campinas: Papirus, 1997.

JOBIM E SOUZA, Solange. Infância e linguagem: Benjamin, Vygotsky e Bakhtin. Campinas: Papirus, 1994.

KASSAR, Mônica de Carvalho M. Deficiência múltipla e educação no Brasil: Discurso e silêncio na história de sujeitos. Campinas: Autores Associados, 1999.

KRAMER, Sonia. Por entre as pedras: Arma e sonho na escola. São Paulo: Ática, 1993.

LACERDA, Cristina B. F. de. Inter-relação entre oralidade, desenho e escrita: O processo de construção do conhecimento. São Paulo: Robe/Cabral, 1995.

MACHADO, Andréa Horta. Aula de química: Discurso e conhecimento. ljuí: Ed. da Unijuí, 2000.

MORATO, Edwiges Maria. Linguagem e cognição: As reflexões de L. S. Vygotsky sobre a ação reguladora da linguagem. São Paulo: Plexus, 1996.

MOURA, Tania Maria de Melo. A prática pedagógica dos alfabetizadores de jovens e adultos: Contribuições de Freire, Ferreiro e Vygotsky. Maceió: Edufal, 1999.

MOYSÉS, Lucia. Aplicações de Vygotsky à educação matemática. Campinas: Papirus, 1997.

PALANGANA, Isilda Campaner. Desenvolvimento e aprendizagem em Piaget e Vygotsky: A relevância do social. São Paulo: Plexus, 1994.

OLIVEIRA, Marta K. de, LA TAILLE, Yves, DANTAS, Heloysa. Piaget, Vygotsky e Wallon: Teorias psicogenéticas em discussão. São Paulo: Summus Ed., 1992. 
OLIVEIRA, Marta K. de. Vygotsky: aprendizado e desenvolvimento - um processo sócio-histórico. São Paulo: Scipione, 1993.

PADILHA, Anna Maria L. Possibilidades de histórias ao contrário ou como desencaminhar o aluno da classe especial. São Paulo: Plexus, 1997.

REGO, Teresa Cristina. Vygotsky - uma perspectiva histórico-cultural da educação. Petrópolis: Vozes, 1995.

SMOLKA, Ana Luiza B., GÓES, Maria Cecília R. de (orgs.). A linguagem e o outro no espaço escolar: Vygotsky e a construção do conhecimento. Campinas: Papirus, 1993.

4. Capítulos de livros:

CARNEIRO, Maria Sylvia Cardoso. "A integração de alunos considerados especiais nas redes públicas de ensino - um olhar Vygotskyano". In: ABRAMOWICZ, Anete; MOLL, Jaqueline (orgs.). Para além do fracasso escolar. Campinas: Papirus, 1997. pp.127- 144.

CRUZ, Maria Nazaré da; SMOLKA, Ana Luiza B. "Gestos, palavras, objetos: Uma análise de possíveis configurações na dinâmica interativa". In: OLIVEIRA, Zilma de M. R. de (org.). A criança e seu desenvolvimento: perspectivas para se discutir a Educação Infantil. São Paulo: Cortez, 1995, p.67-83.

FREITAS, Maria Teresa de A. "Nos textos de Bakhtin e Vygotsky: Um encontro possível". In: BRAIT, Beth (org.). Bakhtin: dialogismo e construção do sentido. Campinas: Ed. da Unicamp, 1997.

GÓES, Maria Cecília R. de; SMOLKA, Ana Luiza B. "A criança e a linguagem escrita: Considerações sobre a produção de textos". In: ALENCAR, Eunice S. de (org.). Novas contribuições da psicologia aos processos de ensino e aprendizagem. São Paulo: Cortez, 1992, pp. 51-70.

GONZALEZ REY, Fernando L. "Psicologia e educação: Desafios e projeções" In: RAYS, Oswaldo Alonso (org.). Trabalho pedagógico: realidades e perpectivas. Porto Alegre: Sulina, 1999.

HENRIQUES, Eda Maria. "O debate Piaget/Vygotsky: Uma contribuição para a questão do conhecimento na pré-escola". In: GARCIA, Re- 
gina Leite (org.). Revisitando a pré-escola. São Paulo: Cortez, 1997, pp. 108-122.

JOBIM E SOUZA, Solange. "Linguagem, consciência e ideologia: Conversas com Bakhtin e Vygotsky". In: OLIVEIRA, Zilma de M. R. de (org.). A criança e seu desenvolvimento: perspectivas para se discutir a Educação Infantil. São Paulo: Cortez, 1995, pp. 11-29.

LANE, Silvia T. M.; CAMARGO, Denise de. "Contribuição de Vigotski para o estudo das emoções". In: LANE, Silvia T. M.; SAWAIA, Bader B. (orgs.). Novas veredas da psicologia social. São Paulo: Brasiliense EDUC, 1995, pp. 115-131.

MACHADO, Maria Lucia de A. "Educação infantil e sócio-interacionismo". In: OLIVEIRA, Zilma de M. R. de (org.). Educação infantil: muitos olhares. São Paulo: Cortez, 1994, pp. 25-49.

MORATO, Edwiges Maria. "A contribuição de Vygotsky para a pesquisa hoje: as relações entre linguagem e cognição e sua repercussão para a pesquisa lingüística”. In: SMOLKA, Ana Luiza B. (org.). Centenário de nascimento de Piaget, Freinet, Vygotsky, Jakobson. Campinas: FE/Unicamp, 1998, pp. 77-92.

OLIVEIRA, Marta K. de. "Sobre diferenças individuais e diferenças culturais: O lugar da abordagem histórico-cultural”. In: AQUINO, Julio G. (org.). Erro e fracasso na escola. São Paulo: Summus, 1997, pp. 45-61.

REGO, Teresa Cristina R. "A indisciplina e o processo educativo: Uma análise na perspectiva vygotskyana". In: AQUINO, Julio G. (org.). Erro e fracasso na escola. São Paulo: Summus, 1997, pp. 45-61.

ROJO, Roxane Helena R. "Contribuições do pensamento de Vygotsky para a pesquisa (em L.A.) hoje". In: SMOLKA, Ana Luiza B. (org.). Centenário de nascimento de Piaget, Freinet, Vygotsky, Jakobson. Campinas: FE/Unicamp, 1998, pp. 65-75.

SMOLKA, Ana Luiza B. "A atividade da leitura e o desenvolvimento das crianças”. In: SMOLKA, Ana Luiza B.; SILVA, Ezequiel Teodoro da; BORDINI, Maria da Glória; ZILBERMAN, Regina. Leitura e desenvolvimento da linguagem. Porto Alegre: Mercado Aberto, 1989, pp.23-41.

SMOLKA, Ana Luiza B. "Modos de inscrição das práticas cotidianas na memória coletiva e individual". In: ZACCUR, Edwiges (org.). A magia da linguagem. Rio de Janeiro: DP\&A, 2000, pp. 75- 99. 


\section{Livros traduzidos:}

BAQUERO, Ricardo. Vygotsky e a aprendizagem escolar. Porto Alegre: Artes Médicas, 1998.

BRASLAVSKI, Berta. Escola e alfabetização. São Paulo: Ed. da Unesp, 1993.

DANIELS, Harry (org.). Vygotsky em foco: Pressupostos e desdobramentos. Campinas: Papirus, 1994.

GARNIER, Catherine; BEDNARZ, Nadine; ULANOVSKAYA, Irina (orgs.). Após Vygotsky e Piaget: Perspectivas social e construtivista, escolas russas e ocidental. Porto Alegre: Artes Médicas, 1996.

LIPMAN, Matthew. Natasha: Diálogos vygotskianos. Porto Alegre: Artes Médicas, 1997.

MOLL, Luis C. Vygotsky e a educação: Implicações pedagógicas da psicologia sócio-histórica. Porto Alegre: Artes Médicas, 1996.

RATNER, Carl. A psicologia sócio-histórica de Vygotsky: Aplicações contemporâneas. Porto Alegre: Artes Médicas, 1995.

VAN DER VEER, René \& VALSINER, Jaan. Vygotsky: Uma síntese. São Paulo: Loyola, 1996.

WERTSH, James V.; DEL RIO, Pablo; ALVAREZ, Amelia. Estudos socioculturais da mente. Porto Alegre: Artes Médicas, 1998.

\section{Artigos de periódicos:}

BEYER, Hugo Otto. "Vygotski: Um paradigma em educação especial". Educação em foco, Juiz de Fora, vol. 4, n. 2, pp. 27-45, set./fev. 1999/2000.

CASTANHO, Maria Eugênia L. M.; COSTA, Eliana A. P. da. "Vygotsky e a formação de professores". Revista de Educação (PUC-Campinas). vol. 3, n. 6, pp. 45-51, jun. 1999.

CASTORINA, Jose Antonio. "Diálogo Piaget - Vygotsky: Aprendizagem de interacão social”. Dois Pontos, Belo Horizonte, vol. 3, n. 27, pp. 1621, jul-ago. 1996. 
CASTORINA, José Antonio. "Piaget e Vygotsky: Novos argumentos para uma controvérsia". Cadernos de Pesquisa, São Paulo, n. 105, pp. 160-183, nov. 1998.

CERISARA, Ana Beatriz. "A educação infantil e as implicações pedagógicas do modelo histórico-cultural". Cadernos Cedes, Campinas, n. 35, pp.65-78, 1995.

CIVILETTI, Maria Vittoria P. "A invasão dos browsers: As novas configurações do sujeito na era da informática". Coletâneas da ANPEPP 4 - Investigação da criança em interação social, Recife, vol.1, n. 4, pp.145-155, set. 1996.

COELHO, Maria Teresa; DIAS, Maria da Graça B. B. "Faz-de-conta social: A ficção se dá pela negociação de significados?" Coletâneas da ANPEPP 4 - Investigação da criança em interação social, Recife, vol.1, n. 4, pp. 95-110, set. 1996.

CURY, Helena Noronha. "As idéias de Lakatos e Vygotsky em uma proposta de mudança para as Licenciaturas em Matemática". Educação Brasileira, Brasília, vol. 19, n. 38, pp. 121-137, jan/jun. 1997.

DAMAZIO, Ademir. "Cognição matemática em sala de aula: Uma abordagem histórico-cultural”. Educação (UFSM), Santa Maria. vol. 22, n. 1, pp. 85-108, 1997.

DAVIS, Cláudia, SOUZA E SILVA, Maria Alice S., ESPÓSITO, Yara. "Papel e valor das interações sociais em sala de aula". Cadernos de Pesquisa, São Paulo, n. 71, pp. 49-54, nov. 1989.

DUARTE, Newton. "Concepções afirmativas e negativas sobre o ato de ensinar". Cadernos Cedes, Campinas, n. 44, pp.85-106, 1998.

ESTEBAN, Maria Teresa. "Repensando o fracasso escolar". Cadernos Cedes, Campinas, n. 28, pp.75-86, 1992.

FERREIRA, Maria Clotilde R.; AMORIM, Katia; VITÓRIO, Telma. "Emergência de novos significados durante o processo de adaptação de bebês à creche". Coletâneas da ANPEPP 4 - Investigação da criança em interação social, Recife, vol. 1, n. 4, pp.111-143, set. 1996.

FERREIRO, Emilia. "Luria e o desenvolvimento da escrita na criança". Cadernos de Pesquisa, São Paulo, n. 88, pp. 72-77, fev. 1994.

FREITAS, Maria Teresa de A. "O ensinar e o aprender na sala de aula". Cadernos para o professor, Juiz de Fora, vol. 6, n. 6, pp. 6-13, 1998. 
FREITAS, Maria Teresa de A. "Vygotsky e Bakhtin: Uma visão intertextual das Ciências Humanas". Vertentes, São João Del-Rei, n. 2, pp. 1830, jul-dez. 1993.

GIUSTA, Agnela S. "A formação social da mente (resenha)". Educação em Revista, Belo Horizonte, n. 1, pp. 45-46, jul. 1985.

GÓES, Maria Cecília R. de. "Critérios para avaliação de noções sobre a linguagem escrita em crianças não alfabetizadas". Cadernos de Pesquisa, São Paulo, n. 49, pp. 3-14, maio 1984.

GÓES, Maria Cecília R. de. "A natureza social do desenvolvimento psicológico". Cadernos Cedes, Campinas, n. 24, pp. 17-24, mar. 1991.

GÓES, Maria Cecília R. de. "Os modos de participação do outro no funcionamento do sujeito". Educação e sociedade, Campinas, vol. 13, n. 42, pp.336-341, ago. 1992.

GÓES, Maria Cecília R. de. "Os modos de participação do outro nos processos de significação do sujeito". Temas em Psicologia, Ribeirão Preto, vol. 1, n. 1, pp. 1-5, 1993.

GÓES, Maria Cecília R. de. "A construção de conhecimentos - examinando o papel do outro nos processos de significação". Temas em Psicologia, São Paulo, n. 2, pp. 23-29, 1995.

GOMES, Maria de Fátima C.; FARIA FILHO, Luciano Mendes de. "Memória e aprendizagem: Uma perspectiva sócio-histórica". Presença Pedagógica, Belo Horizonte, vol. 3, n. 15, po. 43- 50, maio-jun. 1997.

GONZÁLES REY, Fernando. "La categoría 'personalidad: Su significación para la psicología social”. Psicologia Revista, São Paulo, n. 4, pp. 37-53, maio 1997.

GONÇALVES, Francisca dos S. "Aprendizagem, desenvolvimento intelectual e evolução da consciência". Ande, São Paulo, vol. 12, n. 19, pp. 11-16, 1993.

GRAHAN, Loren. "A psicologia materialista dialética de Vygotsky ". Princípios, pp. 52-55, maio-jun. 1994.

JOBIM E SOUZA, Solange; KRAMER, Sonia. "O debate Piaget/Vygotsky e as políticas educacionais". Cadernos de Pesquisa, São Paulo, n. 77, pp. 69-80, maio 1991.

LAGÔA, Ana Mascia. "Cem anos de idéias". Presença Pedagógica, Belo Horizonte, vol. 2, n. 11, pp. 68-73, set.-out. 1996. 
LA TAILLE, Yves de, OLIVEIRA, Marta K. de, DANTAS, Heloysa. "Mesa-redonda: três perguntas a vygotskyanos, wallonianos e piagetianos". Cadernos de Pesquisa, São Paulo, n. 76, pp. 57-64, fev. 1991.

LEITE, Luci B. "As dimensões interacionista e construtivista em Vygotsky e Piaget”. Cadernos Cedes, Campinas, n. 24, pp. 25-31, mar. 1991.

LEITE, Luci B. "Considerações sobre as perspectivas construtivista e interacionista em psicologia”. Idéias, São Paulo, n. 19, pp. 57-65, 1993.

LEWIN, Zaida G. "Uma incursão na zona de desenvolvimento proximal: O resgate da organização dialógica". Psicologia: teoria e pesquisa, Brasília, vol. 9, n. 2, pp. 387-400, 1993.

LIMA, Elvira de S. "Do indivíduo e do aprender: Algumas considerações a partir da perspectiva sócio-interacionista". Educação em Revista, Belo Horizonte, n. 12, pp.14-20, dez. 1990.

LOPES, Therezinha Lourdes. "As interacões sociais e a construcão do conhecimento em Vygotsky " Revista Educacão e Ensino (USF), Bragança Paulista, vol. 1, n. 1, pp. 103-110, mar-ago. 1996.

MACHADO, Nilson José. "Análise do livro Pensamento e linguagem, de L.S. Vygotsky". Revista da Faculdade de Educação/USP, São Paulo, vol. 13, n. 1, pp. 251-257, jan.-jun. 1987.

MAINARDES, Jefferson. "Análise da produção brasileira na perspectiva vigotskiana". Teoria e prática da Educação, Maringá, vol. 1, n. 1, pp. 55-64, set. 1998.

MARTINS, João Batista. "A perspectiva metodológica em Vigotski: o materialismo dialético". Semina-Ciências Sociais e Humanas, Londrina, vol. 15, n. 3, pp.287-295, set. 1994.

MARTINS, João Carlos. "Vigotski e o papel das interações sociais na sala de aula: reconhecer e desvendar o mundo". Idéias, São Paulo, n. 28, pp.111-122, 1997.

MEIRA, Luciano. "Análise microgenética e videografia: ferramentas de pesquisa em psicologia cognitiva". Temas em Psicologia, São Paulo, n. 3, pp. 59-71, 1994.

MELLO, Heliane G. F. de. "Sócio-interacionismo e alfabetização". Dois pontos, Belo Horizonte, vol. 2, n. 14, pp. 73-75, dez. 1992.

MONTOYA, Adrián Oscar D. "Sobre as raízes do pensamento e da linguagem: Vigotski e Piaget”. Cadernos de Pesquisa, São Paulo, n. 92, pp. 26-37, fev. 1995. 
MORATO, Edwiges Maria, COUDRY, Maria Irma. "Processos enunciativodiscursivos e patologia da linguagem: Algumas questões lingüísticocognitivas". Cadernos Cedes, Campinas, n. 24, pp. 66-78, mar. 1991.

MOREIRA, Mércia. "Psicologia soviética e educação: Um debate contemporâneo". Dois pontos, Belo Horizonte, vol. 2, n. 14, pp. 25-27, dez. 1992.

MOSQUERA, Juan J. M; ISAÍA, Silvia. Maria de A. "Vygotsky ou Piaget? uma polêmica de repercussões significativas". Psicologia: reflexão e crítica, Porto Alegre, vol. 2, n. 1-2, pp. 28-36, 1987.

MOTA, Sonia B. V. da. "O lugar da linguagem segundo Vygotsky". Interação, Goiânia, vol. 13, n. 1/2, pp. 1-18, jan-dez 1989.

MOTA, Sonia B. V. da. O lugar da linguagem segundo Vygotsky. Leitura: teoria e prática. v.9, n.16, p.62-75, dez. 1990.

NUNES, Maria Fernanda R.; KRAMER, Sonia. "Teorias do conhecimento e alfabetização: O bebê e a água do banho". Cadernos ESE, Niterói, vol. 1. n. 1, pp.83-88, 1994.

OLIVEIRA, Marta K. de. "A abordagem de Vygotsky: Principais postulados teóricos". In: Secretaria de Educação do Estado de São Paulo. CENP. Piaget e Vygotsky: implicações educacionais. São Paulo: CENP, 1990.

OLIVEIRA, Marta K. de. "Construtivismo em educação: A teoria de Vygotsky". Dois Pontos, vol. 2, n. 11, pp.18-19, set-out. 1991.

OLIVEIRA, Marta K. de. "Vygotsky: Alguns equívocos na interpretação de seu pensamento". Cadernos de Pesquisa, São Paulo, n. 81, pp. 6774, maio 1992.

OLIVEIRA, Marta K. de. "Linguagem e cognição: Questões sobre a natureza da construção do conhecimento". Temas em Psicologia, São Paulo, n. 2, pp. 1-9, 1995.

OLIVEIRA, Marta K. de. "O pensamento de Vygotsky como fonte de reflexão sobre a educação". Cadernos Cedes, Campinas, n. 35, pp. 9-14, 1995.

OLIVEIRA, Marta K. de. Resenha da obra "Natasha: Diálogos vygotskianos". Pátio: Revista pedagógica, Porto Alegre (Ed. Artes Médicas), vol. 1, n. 1, p. 40, maio-jul. 1997.

OLIVEIRA, Zilma de M. R. de. L. S. "Vygotsky: Algumas idéias sobre desenvolvimento e jogo infantil”. Idéias, São Paulo, n. 2, pp. 43-46, 1988.

OLIVEIRA, Zilma de M. R. de. "A natureza do ensino segundo uma perspectiva sociointeracionista”. Ande, São Paulo, vol. 11, n. 18. pp. 37-40, 1992. 
OLIVEIRA, Zilma de M. R. de. "Interações sociais e desenvolvimento: A perspectiva sociohistórica". Cadernos Cedes, Campinas, n. 35, pp. 51-63, 1995.

OLIVEIRA, Zilma de M. R. de. "Interações infantis em creche e a construção de representações sociais de gênero". Coletâneas da ANPEPP 4 Investigação da criança em interação social, Recife, vol. 1, n. 4, pp. 69-82, set. 1996.

PALANGANA, Isilda Campaner. "A função da linguagem ma formação da consciência: Reflexões”. Cadernos Cedes, Campinas, n. 35, pp. 15-28, 1995.

PIAGET, Jean. "Comentários de Piaget sobre as observações críticas de Vygotsky concernentes a duas obras: A linguagem e o pensamento da criança' e 'O raciocínio da criança'”. Em aberto, Brasília, vol. 9, n. 48, pp. 69-77, out./dez. 1990.

PIMENTEL, Alessandra. "Interações sociais e alfabetização: Uma perspectiva sócio-histórica". Psicologia Revista, São Paulo, n. 4, pp. 1126, maio 1997.

PINO, Angel. "A corrente sócio-histórica de psicologia: Fundamentos epistemológicos e perspectivas educacionais". Em aberto, Brasília, vol. 9, n. 48, pp. 61-67, out-dez. 1990.

PINO, Angel. "O conceito de mediação semiótica em Vigotski e seu papel na explicação do psiquismo humano". Cadernos Cedes, Campinas, n. 24, pp. 32-43, mar. 1991.

PINO, Angel. "As categorias de público e privado na análise do processo de internalização". Educação \& sociedade, Campinas, vol. 13, n. 42, pp. 315-327, ago. 1992.

PINO, Angel. "A criança, seu meio e a comunicação: perspectiva sóciohistórica do desenvolvimento". Psicopedagogia, São Paulo, vol. 12, n. 26, pp. 9-15, 1993.

PINO, Angel. "Do gesto à escrita: origem da escrita e sua apropriação pela criança". Idéias, São Paulo, n. 19, pp. 97-110, 1993.

PINO, Angel. "A interação social: perspectivas sócio-históricas". Idéias, São Paulo, n. 20, pp. 49-58, 1993.

PINO, Angel. "Processos de significação e constituição do sujeito". Temas em Psicologia, Ribeirão Preto, vol. 1, n. 1, pp.17-24, 1993.

PINO, Angel. "Semiótica e cognição na perspectiva histórico-cultural". Temas em Psicologia, São Paulo, n. 2, pp. 31-40, 1995. 
PINO, Angel. "A questão da significação - Perspectiva histórico-cultural", Temas em neuropsicologia e neurolingüística vol. 4, S. Paulo: Tec Art Ed. Lta. 1995, pp. 32-38

PINO, Angel. "Constituição e modos de significação do sujeito no contexto da pré-escola". Coletâneas da ANPEPP 4 - Investigação da criança em interação social, Recife, vol. 1, n. 4, pp. 11-32, set. 1996.

PINO, Angel, "A Psicologia Concreta em Vigotski. Contribuições para a Educação”, Psicologia da Educação, S. Paulo, n. 7/8, 1999, pp. 29-52

REDIN, Euclides, MASSAROLO, Adelino. "A teoria histórico-cultural da personalidade". Fórum Educacional, Rio de Janeiro, vol. 13, n. 4, pp. 31-40, set./nov.1989.

REGO, Teresa Cristina R. "A formação social da mente" (resenha). Ande, São Paulo, vol. 11, n. 18, 1992.

REGO, Teresa Cristina R. "A origem da singularidade humana na visão de educadores". Cadernos Cedes, Campinas, n. 35, pp. 7993, 1995.

RIPPER, Afira V. "Significação e mediação por signo e instrumento". Temas em Psicologia, Ribeirão Preto, v.1, n.1, p.25-30, 1993.

ROCCO, Maria Tereza F. "Acesso ao mundo da escrita: Os caminhos paralelos de Luria e Ferreiro". Cadernos de Pesquisa, São Paulo, n. 75, pp. 25-33, nov. 1990.

RocCO, Maria Tereza F. "Pensamento, linguagem e língua materna: Um mapeamento preliminar das posições de Vygotsky, Piaget e Chomsky". Linha d’água, São Paulo, n. 6, pp. 43-50, 1990.

SILVA, Maria do Pilar Cunha e. "A concepção de Vygotsky sobre a relação entre pensamento e linguagem". Revista da FAEEBA, Salvador, vol. 3, n. 3, pp. 169-174, jan-dez. 1994.

SMOLKA, Ana Luiza B. "A prática discursiva na sala de aula: Uma perspectiva teórica e um esboço de análise". Cadernos Cedes, Campinas, n. 24, pp. 51-65, mar. 1991.

SMOLKA, Ana Luiza B. "Múltiplas vozes na sala de aula: Aspectos da construção coletiva do conhecimento na escola". Trabalhos de Lingüística Aplicada, Campinas, n. 18, pp. 15-28, jul-dez.1991.

SMOLKA, Ana Luiza B. "Internalização: Seu significado na dinâmica dialógica". Educação \& sociedade, Campinas, vol. 13, n. 42, pp. 328-335, ago. 1992. 
SMOLKA, Ana Luiza B. "Construção de conhecimentos e produção de sentido: Significação e processos dialógicos". Temas em Psicologia, Ribeirão Preto, vol. 1, n. 1, pp. 7-15, 1993.

SMOLKA, Ana Luiza B. "A concepção de linguagem como instrumento: Um questionamento sobre práticas discursivas e educação formal". Temas em Psicologia, São Paulo, n. 2, pp. 11-21, 1995.

SMOLKA, Ana Luiza B. "Conhecimento e produção de sentidos na escola: A linguagem em foco". Cadernos Cedes, Campinas, n. 35, pp. 41-49, 1995.

SMOLKA, Ana Luiza B.; LAPLANE, Adriana Lia F. de. "O trabalho em sala de aula: Teorias para quê?" Cadernos ESE, Niterói, vol. 1, n. 1, pp. 79-82, 1994.

SPERB, Tania Maria; CONTI, Luciana De. "A construção de papéis sexuais na atividade de brincar". Coletâneas da ANPEPP 4 - Investigação da criança em interação social, Recife, vol. 1, n. 4, pp. 83-94, set. 1996.

TUNES, Elisabeth. "Os conceitos científicos e o desenvolvimento do pensamento verbal”. Cadernos Cedes, Campinas, n. 35, pp. 29-40, 1995.

WERNER, Jairo, ESPÍRITO SANTO, Katia Alves do. "Desenvolvimento e aprendizagem da criança". Revista Brasileira de Crescimento e Desenvolvimento Humano, São Paulo, vol. 1, n. 3, pp. 99-110, 1993.

ZACCUR, Edwiges. "Vygotsky: Um pesquisador à frente de seu tempo". Informação pedagógica, Rio de Janeiro, n. 4, pp. 28-33, s.d.

\section{Nota} tes volumes:

1. - A obra escolhida de Vigotski, em russo, apresenta os seguin-

I - Problemas da teoria e da história da psicologia (1982)

II - Problemas de psicologia geral (1982)

III - Problemas do desenvolvimento mental (1983)

IV - Psicologia da criança (1983)

V - Fundamentos de defectologia (1983)

VI - Herança científica (1984)

Encaminhado para publicação em maio de 2000 